\title{
FABRINCANDO SENTIDOS: $A$ MENINA AVOADA, DE MANOEL DE BARROS, À LUZ DA SEMIÓTICA DISCURSIVA \\ CONSTRUYENDO SENTIDOS: A MENINA AVOADA, DE MANOEL DE BARROS, A LUZ DE LA SEMIOTICA DISCURSIVA
}

Profa. Dra. BATISTOTE, Maria Luceli Faria Universidade Federal de Mato Grosso do Sul UFMS/PPGMEL marialucelifaria@gmail.com

\begin{abstract}
RESUMO: Este trabalho tem por objetivo analisar a infância em Manoel de Barros a partir da perspectiva teórica da Semiótica Discursiva. De modo restrito, objetivamos mobilizar os conceitos semióticos de figuratividade e isotopia no poema "A menina avoada", publicado, em 1999, no livro Exercícios de ser criança. Orientamo-nos pela metodologia de base da teoria semiótica, o percurso gerativo de sentido. Embora haja uma vasta quantidade de trabalhos sobre Manoel de Barros, não há nenhum que discuta a temática da infância à luz da teoria semiótica e que, especificamente, o faça articulando os conceitos supramencionados. Os resultados da análise atestam a eficácia da proposta semiótica na elucidação de como o tema da infância é construído no corpus eleito de forma a assumir certas significações e não outras.
\end{abstract}

PALAVRAS-CHAVE: Manoel de Barros. Infância. Enunciação. Figuratividade. Isotopia.

RESUMEN: Este trabajo tiene como objetivo analizar la infancia en Manoel de Barros desde la perspectiva teórica de la semiótica discursiva. De modo restrictivo, objetivamos movilizar los conceptos semióticos de la figuratividad y la isotopía en el poema "A menina avoada", publicado, en 1999, en el libro Exercício de ser criança. Nos guiamos por la metodología básica de la teoría semiótica, el recorrido generativo de sentido. Aunque hay una gran cantidad de trabajos a respecto de Manoel de Barros, no hay ninguno para discutir el tema de la infancia a luz de la teoría semiótica y, específicamente, que articule los conceptos ya mencionados. Los resultados del análisis muestran la eficacia de la propuesta semiótica en la elucidación de cómo el tema de la infancia se construye en el corpus elegido para asumir ciertos significados y no otros.

PALABRAS CLAVE: Manoel de Barros. Infancia. Enunciación. Figuratividad. Isotopía.

\section{Notas introdutórias}

Manoel de Barros carrega em sua trajetória artística o desenvolvimento de uma poética absolutamente singular. Por meio da ludicidade, do remanejo realizado com a linguagem e com o vernáculo rupestre, o poeta mato-grossense (re)inventa o universo pantaneiro. É peculiar em sua poesia as efemeridades da vida receberem importância crucial, tudo o que é dado como sem importância, como descartável, passadiço é recolhido pelo artista e transformado em matéria para poesia. Por essa razão, a temática infância é recorrente em toda a sua obra, podendo ser considerada como um dos pilares de sua poética.

Nesse sentido, objetivamos analisar a infância em Manoel de Barros sob a égide da Semiótica Discursiva, especificamente, nos propomos a examinar o conceito de figuratividade e isotopia no poema "A menina avoada", composição integrante do livro 
Exercícios de ser criança, primeira obra do poeta direcionada ao público infantil. ${ }^{1}$ Para alcançar os objetivos elencados, recorremos ao aporte metodológico proposto pela teoria semiótica, o percurso gerativo de sentido. Devido a isso, interessamo-nos não em analisar o que significa a infância na poesia manoelina, mas como essa significação é construída. Partimos do pressuposto de que toda organização figurativa manifesta os valores do enunciador, os quais podem ser encontrados a partir das marcas e traços linguísticos deixados no enunciado, conferindo ao discurso determinados efeitos de sentido.

Face à extensa fortuna crítica no campo dos estudos literários dedicada a obra de Manoel de Barros, bem como à temática infância, marcante em sua produção, percebese que não há estudos no campo da semiótica discursiva que tenham se dedicado ao trabalho do poeta, especialmente no tocante a mobilização dos conceitos de figuratividade e isotopia articulados a essa temática. É possível encontrar trabalhos acerca da infância retratada pelo poeta mato-grossense ancorados em referenciais teóricos na área da educação e da literatura, como a dissertação de mestrado "Exercício de ser humano: a poesia e a infância na obra de Manoel de Barros" ${ }^{2}$ " defendida por Mirian Garcia em 2006 e o artigo "Imagens da infância para (re) pensar o currículo" 3" de Walter Kohan.

\section{Enunciação e figuratividade}

Hoje amarrei no rosto das palavras minha máscara. Faço o que posso.

Manoel de Barros

As linhas de um texto são capazes de nos conduzir a um universo de infinitas significações, possibilita que o leitor possa adentrar em um mundo fictício pensando ser ele real, permite a construção de pássaros que vestem casacos dourados como sol, de rãs que participam de teatro, de caixotes que se transformam em carroça. Percebemos, assim, que enunciar é criar visões e (re)visões do mundo, é justamente amarrar no rosto das palavras uma máscara, marcando-se no discurso, combinando e recombinando os signos da língua com vistas a assiná-la para que ela torne-se mais particular. Como

\footnotetext{
${ }^{1}$ Em nosso trabalho, utilizamos a versão original do poema, publicada em 1999 pela editora Salamandra.

${ }^{2}$ GARCIA, Mirian Theyla Ribeiro. Exercício de ser humano: a poesia e a infância na obra de Manoel de Barros. 2006. 125 f. Dissertação (Mestrado em Literatura Brasileira) -Universidade de Brasília, Brasília, 2006. Disponível em: < http://repositorio.unb.br/handle/10482/1962〉. Acesso em: 20 jul. 2016.

3 KOHAN, Walter Omar. Imagens da infância para (re) pensar o currículo. 2003. Revista SulAmericana de Filosofia e Educação, 2003. Disponível em: < http://www.periodicos.unb.br/index.php/resafe/article/view/5409>. Acesso em: 20 jul. 2016.
} 
assevera Émile Benveniste (1995, p.285), "a linguagem ensina a própria definição do homem", nela e por ela o homem se constitui como sujeito. É válido ressaltar que ao nos valermos dos termos homem e sujeito não partimos de uma visão ontológica, mas nos referimos ao sujeito linguisticamente construído no discurso. Logo, as reflexões realizadas não têm por objetivo dissertar a respeito de Manoel de Barros, mas do sujeito da enunciação marcado em seus poemas.

Vimos que a metodologia de base deste trabalho é o percurso gerativo de sentido. Nas palavras de Barros (2005) essa ferramenta metodológica é, pois, uma sucessão de patamares, cada um passível de receber uma descrição apropriada, que evidencia como se produz e se interpreta o sentido, num processo que parte do mais simples ao mais complexo. Por essa razão, ele organiza-se em três patamares: o fundamental, o narrativo e o discursivo. $\mathrm{O}$ estudo da figuratividade situa-se no terceiro nível, o discursivo.

Este patamar subdivide-se em dois níveis: o da sintaxe e o da semântica. Na sintaxe discursiva a narrativa domina os estudos relativos à colocação em discurso das categorias de pessoa, tempo e espaço, são os processos de debreagem e embreagem. A debreagem pode ser enunciva ou enunciativa. Elas criam, em princípio, dois grandes efeitos de sentido: de objetividade e subjetividade. Há também a debreagem interna ou de $2^{\circ}$ grau que ocorre quando "um actante já debreado, seja ele da enunciação ou do enunciado, se torna instância enunciativa, que opera, portanto, uma segunda debreagem, que pode ser enunciativa ou enunciva" (FIORIN, 1995, p.7). Um exemplo clássico de debreagem interna é o diálogo. A embreagem, por sua vez "é a expulsão fora da instância de enunciação da pessoa, do espaço e do tempo enunciado, "é o efeito de retorno à enunciação"” (ibidem). Em nossa pesquisa, mobilizaremos apenas a noção de debreagem.

Já na semântica discursiva, os valores trazidos no nível narrativo são difundidos no discurso de forma abstrata, por meio de percursos temáticos que, por sua vez, podem ser figurativizados, alcançando com isso maior concretude. É válido ressalvar que o nível da sintaxe e da semântica são separados por fins metodológicos. Não significa, portanto, que apenas temas e figuras revestem o discurso de concretude e significação, o mecanismo de debreagem é imprescindível à atribuição de significância textual. Defendemos, então, que os domínios sintáxicos e semânticos nutrem-se mutuamente e em conjunto constroem um simulacro do mundo natural. 
A figuratividade consiste numa operação enunciativa que revela as crenças, os valores e a posição do sujeito da enunciação, afirma Fiorin (2012). Isto porque quando um texto é figurativizado uma imagem do mundo é desenhada a fim de projetar certos efeitos de sentido.

O termo figuratividade, originalmente, advém da teoria estética, "que opõe, como todos sabem a arte figurativa e a arte "não-figurativa' ou 'abstrata", (BERTRAND, 2002, p.154). Diz respeito a semelhança formalmente estabelecida com o mundo sensível. Por isso, quanto mais figurativo for um discurso, maior será o efeito de realidade criado. Assim, a figura é todo conteúdo pertencente a qualquer língua natural ou a qualquer sistema de representação que possua um correlato perceptível no mundo natural efetivamente real, bem como no mundo natural construído.

Não é sem razão, portanto, que os textos literários são classificados como fundamentalmente figurativos, confirmam Greimas e Courtés (1979, p.185): “Quando se tenta classificar o conjunto dos discursos em duas grandes classes, discursos figurativos e não figurativos (ou abstratos), percebe-se que a quase totalidade dos textos ditos literários e históricos pertence à classe dos discursos figurativos”. Isso porque o discurso literário comporta em sua essência uma linguagem figurativa por meio da qual se dá a construção de imagens do mundo:

Sendo a literatura uma linguagem figurativa que cria simulacros do mundo
natural, sendo as formas literárias um repertório de possibilidades discursivas
e textuais, sugere ela a possibilidade de novas ordens no que diz respeito aos
dois grandes sistemas de significação: mostra a possibilidade de novos
mundos naturais, de outras realidades, de diferentes visões de mundo e, ao
mesmo tempo, indica que são possíveis novas ordens linguísticas e
discursivas diversas da realidade automatizada e rotineira do discurso
comum. Essas duas possibilidades imbricam-se na materialidade da
linguagem figurativa. (FIORIN, 2012, p.54).

Como se pôde notar a partir dos apontamentos acima, a figuratividade opõe-se à abstração, ou, em termos semióticos, à tematização. O tema é uma atribuição semântica, de ordem puramente conceptual, que não alude ao mundo natural. Os temas são classes que organizam, classificam e ordenam os componentes do mundo natural, tais como o amor, a vergonha, o orgulho, a moda, a natureza, a cultura etc. É importante salientar que temas e figuras não são conceitos dicotômicos, mas complementares. Por isso, um texto não é composto de figuras estanques, ao contrário, elas estabelecem uma relação entre si. 
Conforme assegura Fiorin (2002), numa análise textual o que tem valia é esse encadeamento de figuras, o qual é denominado percurso figurativo. Decifrar um percurso figurativo é encontrar o tema que lhe é subjacente, para que um grupo de figuras faça algum sentido é necessário que esteja recobrindo algum tema. As figuras "caixote", "lata de goiabada", "bois" e "corda de embira" não fazem o menor sentido se pensadas isoladamente, contudo, se as associarmos ao tema infância, por exemplo, é possível chegar a uma interpretação coerente. Assim como o percurso figurativo, o encadeamento de temas é denominado de percurso temático. Com base nesses discorrimentos, torna-se clarividente que o recobrimento temático e figurativo, realizado pelo sujeito da enunciação, produz efeitos de realidade e assegura a relação entre mundo e discurso.

\section{A permanência de sentido: efeito isotópico}

A recorrência de temas e figuras ao longo do discurso denomina-se isotopia. Esse conceito foi tomado por Greimas do domínio da físico-química em que originariamente significava "propriedade dos nuclídeos que possuem o mesmo número atômico, mas cujos números de massa são distintos" (Dicionário Eletrônico Houaiss, 2001). No campo semiótico, a isotopia constitui um crivo de leitura que torna homogênea a superfície do texto (Greimas e Courtés, 1979).

Reconhecem-se dois tipos de isotopia: a temática e a figurativa. Aquela se manifesta na recorrência de unidades semânticas abstratas em um mesmo percurso temático. Somente é possível inferir sobre o que um texto aborda a partir do reconhecimento da isotopia temática. Assim, quando lemos uma notícia e afirmamos se tratar de um assunto relativo à corrupção ou quando assistimos a um filme e identificamos ser um romance, realizamos o reconhecimento da isotopia temática.

Por sua vez, a isotopia figurativa distingue os discursos integralmente recobertos por um ou mais percursos figurativos. Conforme Barros (2002), a reincidência de traços figurativos, a integração de figuras semelhantes confere ao discurso o caráter da realidade ou pode criar a ilusão total do irreal.

\section{A menina avoada: uma leitura semiótica}

O poema "A menina avoada" compõe a obra Exercícios de ser criança. Lançada em 1999, esta foi a primeira publicação de Manoel de Barros direcionada ao público 
infantil e conta com as ilustrações do grupo Matizes Dumont, formado por bordadeiras e um bordadeiro da mesma família, naturais da cidade de Pirapora, Minas Gerais. Os artistas dedicam-se às artes visuais têxteis e desenvolvem projetos sociais em que a linguagem é o bordado. O interessante na produção artística do grupo é justamente a substituição das ferramentas que usam em seu fazer artístico. Tintas e pincéis são deixados de lado para que agulha e linha possam materializar suas criações. Percebemos, então, a singularidade dessa forma de arte, cada escolha de linha, agulha, tipo de bordado marca sua artesanal assinatura.

A eleição dessa forma de iluminura, o bordado, para compor um livro infantil pode causar certo estranhamento, uma vez que é incomum ao gosto das crianças, porém a escolha das cores, a dinamicidade e o relevo das imagens faz aflorar variadas sensações, desperta no leitor uma vontade de interagir com a obra ao ponto de querer tocá-la, sentir o efeito de cada tipo de linha, das miçangas, dos bordados feitos pelo avesso. Sabemos que a criança explora sua imaginação de forma muito mais ampla do que os adultos, sendo capaz de alterar e recriar o universo natural. Apresentamos abaixo o poema na íntegra:

\section{A menina avoada}

Foi na fazenda de meu pai antigamente

Eu teria dois anos; meu irmão, nove.

Meu irmão pregava no caixote duas rodas de lata de goiabada.

A gente ia viajar.

As rodas ficavam cambaias debaixo do caixote:

Uma olhava para a outra.

$\mathrm{Na}$ hora de caminhar

as rodas se abriam para o lado de fora.

De forma que o carro se arrastava no chão.

Eu ia pousada dentro do caixote com as perninhas encolhidas.

Imitava estar viajando.

Meu irmão puxava o caixote

por uma corda de embira.

Mas o carro era diz-que puxado por dois bois.

Eu comandava os bois:

- Puxa, Maravilha!

- Avança, Redomão!

Meu irmão falava

que eu tomasse cuidado

porque Redomão era coiceiro.

As cigarras derretiam a tarde com seus cantos.

Meu irmão desejava alcançar logo a cidade -

Porque ele tinha uma namorada lá.

A namorada do meu irmão dava febre no corpo dele. 
Isso ele contava.

No caminho, antes, a gente precisava

de atravessar um rio inventado.

$\mathrm{Na}$ travessia o carro afundou

e os bois morreram afogados.

Eu não morri porque o rio era inventado.

Sempre a gente só chegava no fim do quintal

E meu irmão nunca via a namorada dele -

Que diz-que dava febre em seu corpo.

A partir de sua leitura, percebemos a predominância figurativa subjacente, os elementos figurativos e as estratégias discursivas mobilizadas contribuem para fabrincar os efeitos de sentido gerados a partir de cada leitura. Entretanto, nosso alvo não se limita a classificações e categorizações discursivas, é necessário compreender quais mecanismos foram utilizados pelo o sujeito da enunciação para figurativizar seu enunciado. No nível sintáxico-discursivo, as escolhas de pessoa, espaço e tempo instauram uma debreagem enunciativa, conferindo ao poema o efeito de subjetividade, mais do que isso, faz com que pareça ser uma memória. O poema tem como ponto de referência o "eu", instância enunciativa por excelência, marcado linguisticamente pelo uso do pronome possessivo e pronome pessoal do caso reto na primeira pessoa do singular: "Foi na fazenda de meu pai antigamente/Eu teria dois anos; meu irmão, nove”. A escolha do tempo verbal é imprescindível para determinação de certos efeitos de sentido. No poema, o uso do pretérito imperfeito é predominante (meu irmão pregava, ficavam cambaias, imitava, puxava o caixote, etc).

Fiorin (2001, p.155), ancorado no pensamento de Bakhtin acerca do pretérito imperfeito, afirma que através do uso desse tempo verbal, pelo enunciador, o olhar do enunciatário é direcionado para o interior, para o processo de constituição, por isso, "vê os estados e as transformações indicados por esse tempo em curso ao longo de um espaço de tempo, [...] a ação é considerada como inacabada, contínua dentro da continuidade do momento de referência". Nesse sentido, a escolha dessa forma temporal do verbo faz com que as peripécias narradas atinjam um teor de repetitividade, assinalando sua existência na cotidianidade dos sujeitos.

O efeito de realidade é construído no texto, também, por meio da debreagem interna: “Eu comandava os bois:/ - Puxa, Maravilha!l - Avança, Redomão!”. Percebemos nesse mesmo trecho a instauração de uma debreagem interna, os travessões e os pontos de exclamação materializam a fala da criança durante sua brincadeira, valendo-se de um fazer parecer verdadeiro. 
Lembrando que em semiótica a verdade encontra fundamento no conceito de veridicção que diz respeito a uma espécie de contrato entre o enunciador e o enunciatário do discurso enunciado, independentemente de qualificarem-se como autor e leitor reais, já que se trata de algo interno ao texto:

\begin{abstract}
A "verdade", para ser dita e assumida, tem de deslocar-se em direção às instâncias do enunciador e do enunciatário. Não mais se imagina que o enunciador produza discursos verdadeiros, mas discursos que produzem um efeito de sentido "verdade": desse ponto de vista, a produção da verdade corresponde ao exercício de um fazer cognitivo particular, de um fazer parecer verdadeiro que se pode chamar, sem nenhuma nuance pejorativa, de fazer persuasivo. Exercido pelo enunciador, o fazer persuasivo só tem uma finalidade: conseguir a adesão do enunciatário. (GREIMAS \& COURTÉS, Op. cit.,1979, p. 487).
\end{abstract}

A categoria espacial, referenciada na pessoa subjetiva, confirma o espaço do lá em oposição ao espaço do aqui marcado pelo sujeito enunciador (Foi na fazenda; no fim do quintal). Entretanto, há um acontecimento discursivo muito interessante, nos versos "Meu irmão desejava alcançar logo a cidadel - Porque ele tinha uma namorada lá", percebemos a instauração de um espaço ainda mais distante: a cidade. Ela figura o lugar alheio, longínquo da própria realidade rural dos sujeitos participantes do evento narrado.

No campo semântico, é notória a riqueza temática e figurativa subjacente ao poema. A figuratividade se constrói de forma sumamente concreta, por meio das figuras utilizadas somos transportados ao universo rupestre de faz-de-conta. Como vimos, a organização figurativa de um texto necessita ser recoberta por um tema para fazer algum sentido.

A infância é a temática predominante no poema, essa afirmação pode ser justificada com base no percurso figurativo do texto, marcado por figuras como "eu teria dois anos;/meu irmão nove", "eu ia pousada dentro do caixote,/ com as perninhas encolhidas./Imitava estar viajando.", as quais ilustram o momento em que estão justamente construindo a infância, fabrincando um modo de ser criança particular, figurativizado pelas brincadeiras entre dois irmãos, mas não são quaisquer brincadeiras, elas envolvem o imaginário infantil, materializado linguisticamente por meio das figuras "imitava", "rio inventado" e pela construção "diz-que". A designação para esta expressão conforme o dicionário eletrônico Infopédia é "conjunto de mexericos; intriga, falatório". Conforme o uso popular, essa é uma expressão para referir-se a histórias duvidosas, não muito críveis, o que contribuiu para arrematar a impressão do faz de conta que perpassa todo o texto. É interessante observar que para Peter Hunt 
(2010), nos livros infantis é comum a recorrência de temas como magia, fantasia, simplicidade e aventura, uma vez que a criança tem na brincadeira um elemento natural de seu perfil e, por isso, verá a linguagem como outro espaço de exploração lúdica.

Poderia, talvez, causar algum estranhamento limitarmos a temática do poema à infância. Sabemos da possibilidade de em um mesmo texto concorrerem várias temáticas, em nossa análise, por exemplo, os temas natureza, diversão, recordação, amor platônico, família estão presentes também. Entretanto, ao longo da cadeia discursiva, percebemos a reincidência de traços semânticos que apontam a presença de duas isotopias predominantes: a isotopia da infância e a isotopia da natureza.

A coexistência de ambas é determinante à significação global de todo o poema. Isto porque a infância retratada não é geral, comum a todos, ela está situada em um contexto específico, o rural, marcadamente oposto ao urbano. A recordação do sujeito enunciador figurativizado por uma menina, como se constata no trecho "eu ia pousada" e no título do poema "A menina avoada", remete a um modo singular de ser criança, o qual envolve elementos da natureza como cigarras, bois e rios.

Até mesmo o imaginário, explorado pelas crianças de modo ilimitado e criativo, tem no poema suas raízes arraigadas ao universo rupestre ilustrado pela figura do carro de boi que na realidade era apenas um caixote com latas de goiabada, puxado pelo irmão cuja intenção era atravessar o rio inventado para ver sua suposta namorada, todas essas figuras verbais coadunam-se às figuras ilustrativas que constroem o poema. De modo que os bordados que ilustram A menina avoada são determinantes para o alcance de maior nível de iconicidade na figurativização da infância projetada pelo sujeito da enunciação: 


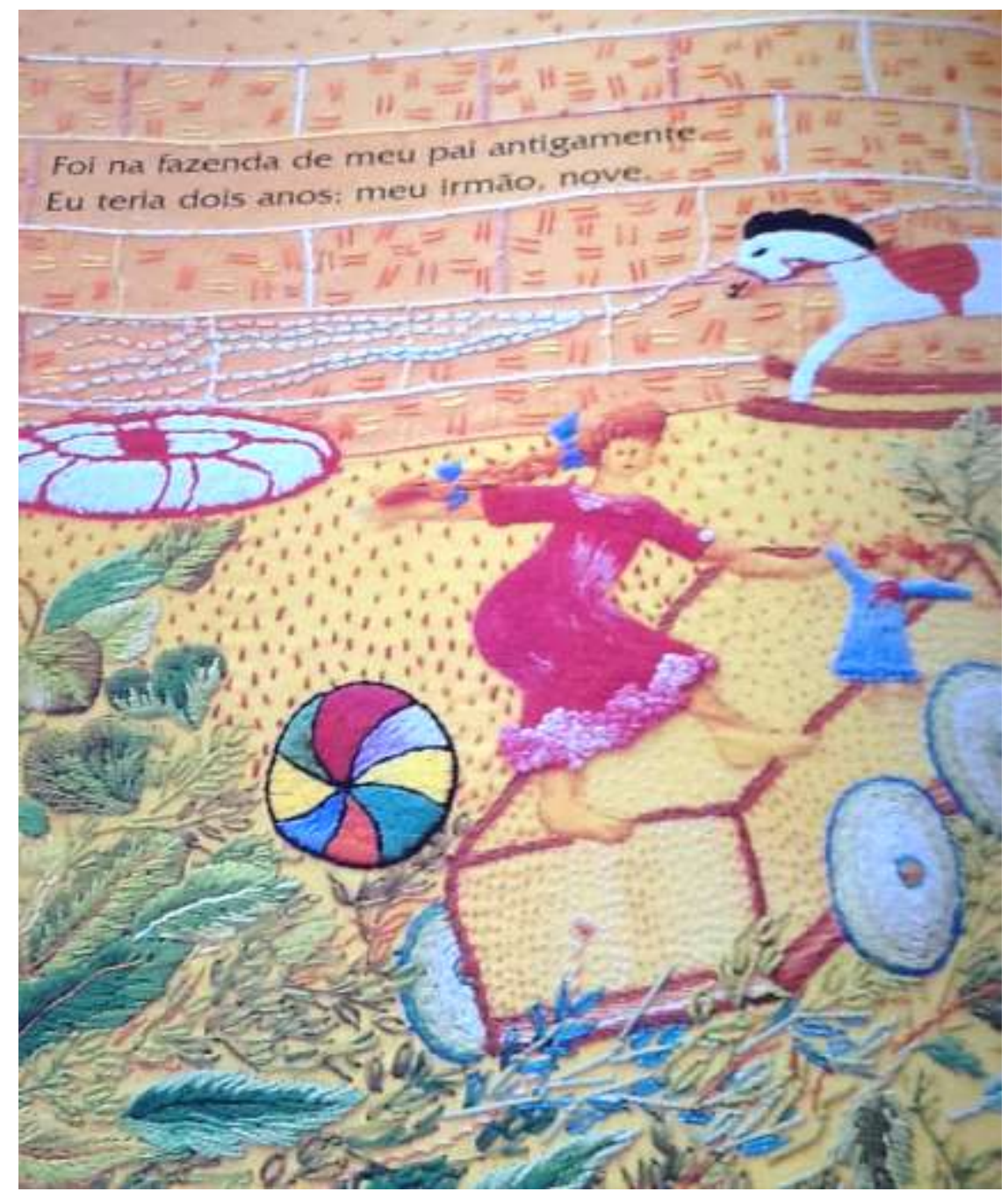

Figura 1: A carroça e os bois 


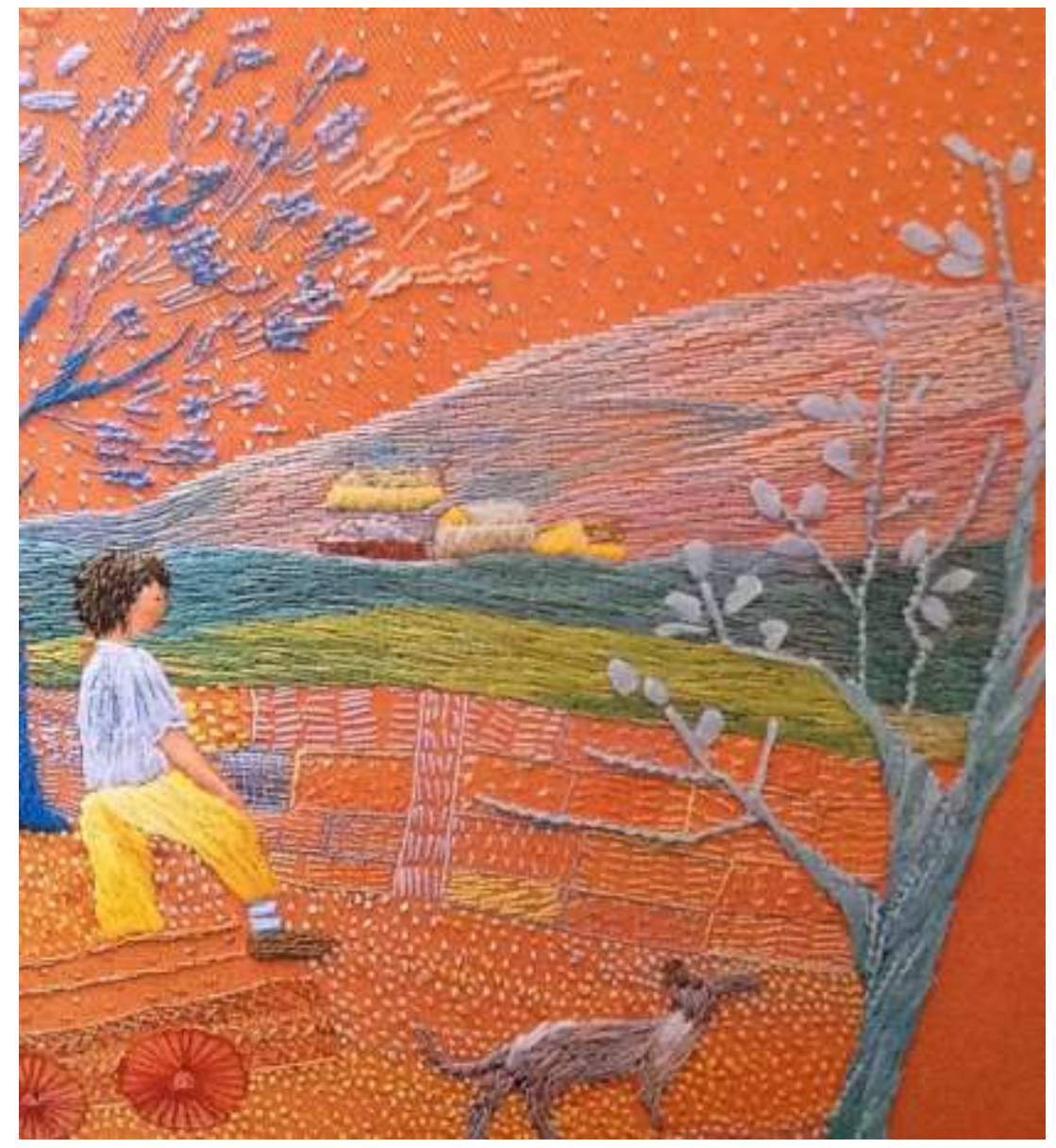

Figura 2: 0 fim do quintal

Lembrando que quanto maior for o nível de iconicidade, maior será a densidade do componente figurativo, nas palavras de Bertrand (op cit, 2003) haverá manifestação icônica quando a reunião de traços característicos for suficiente para permitir sua interpretação como uma representação do mundo natural. Na figura 1, vemos a projeção imagética da "menina avoada" equilibrando-se por cima da carroça inventada, cercada por elementos que aludem ao universo da inocência, do lúdico tais como a bola, o cavalinho de madeira, a boneca de pano.

Se a infância é demarcada no texto, podemos afirmar que o rural é sublinhado com linhas coloridas e laranjadas como a cor do sol ao se deitar no horizonte da fazenda. Com a figura 2, confirma-se o olhar distante do irmão situado espacialmente "no fim do quintal", como quem vislumbra algo muito valioso, do seu ponto de vista, configurando-se como um sujeito virtualizado, isto é, ele /quer/ fazer (chegar a cidade para ver sua suposta namorada), porém não /pode/ efetuar essa performance, já que ela existe somente em sua fantasia de menino. 


\section{Considerações finais}

Nosso trabalho se propôs a analisar a temática da infância em Manoel de Barros a partir da mobilização dos conceitos de figuratividade e isotopia no poema "A menina avoada". Percebemos que essas noções semióticas foram capazes de elucidar como a infância é fabrincada na poética barreana, por meio da apresentação das estratégias linguístico-discursivas mobilizadas pelo sujeito da enunciação.

A análise apontou para configuração de uma infância peculiar, com raízes rurais. Além disso, confirmou-se sobremaneira a presença do imaginário, do lúdico, do faz de conta como elementos de figurativização do que entende-se por ser criança sob a perspectiva do enunciador. Acreditamos que esse trabalho não exauriu a riqueza encontrada na obra do poeta mato-grossense, ao contrário, por meio dele é possível vislumbrar novos caminhos para pesquisa a partir de novos enfoques semióticos.

\section{REFERÊNCIAS}

BARROS, Manoel de. Exercícios de ser criança. Ilustrações e bordados de Antônia Zulma Diniz, Ângela, Marilu, Martha e Sávia Dumont sobre os desenhos de Demóstenes. Rio de Janeiro: Salamandra, 1999.

BARROS, Diana Luz Pessoa de. Teoria do discurso: fundamentos semióticos. São Paulo: Humanitas, 2002.

Teoria Semiótica do texto. São Paulo: Ática, 2005.

BENVENISTE, Émile. Problemas de lingüística geral I. $4^{\text {a }}$ ed. Campinas: Pontes/ EdUNICAMP, 1995.

BERTRAND, Denis.. Caminhos da semiótica literária. Tradução do Grupo CASA. Bauru, SP: EDUSC, 2003.

Dicionário infopédia da Língua Portuguesa com Acordo Ortográfico [em linha]. Porto: Porto Editora, 2003-2016. Disponível na Internet: https://www.infopedia.pt/dicionarios/lingua-portuguesa/diz-que-diz. Acesso em: 21 out. 2016.

FIORIN, José Luiz. A pessoa desdobrada. Alfa: São Paulo, 1995. Disponível em: <http://seer.fclar.unesp.br/alfa/article/view/3968/3643>. Acesso em: 29 jul. 2016.

Elementos de análise do discurso. São Paulo: Contexto, 2002.

As astúcias da enunciação: as categorias de pessoa, espaço e tempo. 2. ed. São Paulo, SP: Atica, 2001.

Em busca do sentido: estudos discursivos. São Paulo: Contexto, 2012.

GREIMAS, Algirdas J.; COURTÈS, Joseph. Dicionário de semiótica. São Paulo, Cultrix,1979. 
HOUAISS, A. Dicionário eletrônico Houaiss da língua portuguesa. Rio de Janeiro: Objetiva. Versão 1.0. 1 [CD-ROM]. 2001.

HUNT, Peter. Crítica, teoria e literatura infantil. Tradução de Cid Knipel. São Paulo: Cosacnaify, 2010. Disponível em: <https://pt.scribd.com/document/323672387/Criticateoria-e-literatura-infantil-Hunt-Peter-pdf>. Acesso em: 19 out. 2016. 